\title{
Influence of Light-Curing Unit Systems on Shear Bond Strength and Marginal Microleakage of Composite Resin Restorations
}

\author{
Juliano Fernandes Sassi, Andrigo dos Reis Batista, Juliane Cristina Ciccone-Nogueira*,
} Silmara Aparecida Milori Corona, Regina Guenka Palma-Dibb*

\author{
Departament of Restorative Dentistry, School of Dentistry, University of São Paulo -USP, \\ Av. do Café, S/N Monte Alegre, 14040-904 Ribeirão Preto - SP, Brazil
}

Received: August 16, 2007; Revised: March 11, 2008

\begin{abstract}
The aim of the present study was to evaluate the influence of different photopolymerization (halogen, halogen soft-start and LED) systems on shear bond strength (SBS) and marginal microleakage of composite resin restorations. Forty Class V cavities (enamel and dentin margins) were prepared for microleakage assessment, and 160 enamel and dentin fragments were prepared for the SBS test, and divided into 4 groups. Kruskal-Wallis and Wilcoxon tests showed statistically significant difference in microleakage between the margins $(\mathrm{p}<0.01)$ with incisal margins presenting the lowest values. Among the groups, it was observed that, only at the cervical margin, halogen soft-start photo polymerization presented statistically significant higher microleakage values. For SBS test, ANOVA showed no statistical difference $(\mathrm{p}>0.05)$ neither between substrates nor among groups. It was concluded that Soft-Start technique with high intensity end-light influenced negatively the cervical marginal sealing, but the light-curing systems did not influence adhesion.
\end{abstract}

Keywords: enamel, dentin, microleakage, adhesion, photopolymerization devices

\section{Introduction}

Long-term success of composite resin restorations is directly related to accurate polymerization, which is crucial to obtain optimal physicochemical properties. Polymerization reaction occurs when there is light incidence with a wavelength within absorption spectrum of the photoinitiator and with enough intensity to keep it at the excitation state, thus enabling it to react with the reduction agent (Amina-N) and form free radicals for a cascade reaction to begin ${ }^{1,2,3}$.

In addition to wavelength, light intensity is also important to the polymerization process and it influences the mechanical properties of composite resin ${ }^{4,5}$ because is directly related to monomer-polymer conversion rate, which is determined by the number of double carbon bonds converted into single bonds. The polymerization of the resin matrix produces a gelatinization state, in which the restorative material is transformed from a viscous-plastic into a rigid-elastic phase $^{6,7}$.

Current light-curing units can vary a lot with respect to light intensity, reaching values as high as $1,800 \mathrm{~mW} . \mathrm{cm}^{-2}$, which allows less polymerization time with improved physical properties. However, high light intensities may increase dental structure temperature ${ }^{8}$ and polymerization shrinkage, thus producing internal tensions and possible crack propagation at tooth/restoration interface, which would lead to marginal microleakage $\mathrm{e}^{2,9}$.

In view of this, newer devices and polymerization techniques have been developed in an attempt to minimize the stress caused by polymerization shrinkage and to improve composite resin mechanical properties. The Soft-Start polymerization technique has been introduced as a system that reduces the initial conversion, which controls the flowability of the composite resins ${ }^{10,11}$. This slow polymerization reaction influences the flow characteristics and may be useful in attenuating the shrinkage stresses and improving marginal adaptation. Subsequently, high light intensities are necessary for completing polymerization, reaching optimal mechanical properties ${ }^{12}$, and increasing marginal integrity of composite restorations $\mathrm{s}^{11,13}$.

Another system that has being employed for composite polymerization is the LED (light-emitting diode), a semi-conductive device composed by several semi-conductive layers that emit light when a tension is applied between these layers. LED system promotes a light with spontaneous emission and polychromatic in a narrow wavelength range $e^{2,14}$. LEDs present important characteristics such as: tension/intensity relation of current favorable for use in low tensions, enabling evolution of battery source devices; long life span without power loss; spectral emission coincident with composite resin photoinitiator, and no need of using optical filter. In addition, there is minimal temperature rise during curing compared to halogen lamps $\left(10 \text { to } 16^{\circ} \mathrm{C}\right)^{15,16}$.

There are several options of visible light curing units on the market, with different light intensities and spectra, aiming at improving the material's properties, decreasing the exposure time and reducing the working time ${ }^{17}$. Further studies are necessary to assess the influence of newer polymerization sources on the properties of the different composites available. Therefore, the aim of this study was to assess in vitro the influence of different light-curing systems on the shear bond strength of a composite resin system to bovine enamel and dentin substrates and the marginal microleakage of class $\mathrm{V}$ composite resin restorations.

\section{Method and Material}

Four light-curing systems were used: group I (control)- conventional halogen lamp (XL-3000; 3M Dental Products- St Paul, MN 55144- USA); group II- halogen soft-start system (JetLite 4000; J. Morita- 9 Manson Irvine, CA 92618- USA); group III- halogen softstart system CL-K200 (Kondortech Equip. Odont. Ldta- São Carlos, CEP 13563-410 Brazil); and group IV- LED light, Ultraled (Dabi Atlante S.A. Ind. Med. Odontológica- Rib Preto, CEP 14095-000 Brazil) (Table 1).

Fresh bovine incisors were stored in chloramine solution at $4{ }^{\circ} \mathrm{C}$ during 48 hours, and then washed in tap water and cleaned with periodontal curettes. A total of 60 teeth were selected and kept stored in distilled water at $4{ }^{\circ} \mathrm{C}$ until use. 
Table 1. Tested parameter description.

\begin{tabular}{llll}
\hline Photopolymerization devices & \multicolumn{1}{c}{ Wavelength } & Type of light / Curing modes & Power density \\
\hline XL 3000 (Group I) & Approximately $500 \mathrm{~nm}$ & Halogen / Continous & $500{\mathrm{~mW} . \mathrm{cm}^{-2}}^{-2}$ \\
Jet Lite 4000 (Group II) & 400 to $520 \mathrm{~nm}$ & Halogen / Soft-Start & 50 to $1200 \mathrm{~mW} . \mathrm{cm}^{-2}$ \\
CL-K200 (Group III) & 400 to $500 \mathrm{~nm}$ & Halogen / Soft-Start & 50 to $600 \mathrm{~mW} . \mathrm{cm}^{-2}$ \\
Ultraled (Group IV) & 450 to $480 \mathrm{~nm}$ & LED / Continous & $130 \mathrm{~mW} . \mathrm{cm}^{-2}$ \\
\hline
\end{tabular}

\subsection{Microleakage testing}

Forty incisors had their apices sealed with a light-cured composite. Class V cavity was prepared at buccal surface, with incisal margins in enamel and cervical margins in dentin/cementum.

Cavities were prepared using water-cooled \#245 carbide bur (JET Brand, Beavers Dental- Morrisburg, Box 900- Canada) attached to a high-speed handpiece (Silent MRS, Dabi Atlante S.A. Ind. Méd. Odontológica, Ribeirão Preto, SP, Brazil). Cavities were finished with the same bur at low speed. Burs were replaced after every 5 preparation. The bevel was done at enamel cavity margin using a diamond bur \#1190 (KG Sorensen Ind. e Com. Ltda- Barueri, CEP 06465-130- Brazil). After preparation, teeth were randomly assigned to 4 groups $(n=10)$, according to the light-curing system (Table 1). Cavity dimensions were: $4 \mathrm{~mm}$ mesiodistal distance, $3 \mathrm{~mm}$ gingivoincisal height and cavity depth was fixed at $2 \mathrm{~mm}$ using a periodontal probe.

Surfaces were etched with a $35 \%$ phosphoric acid gel (Etching Gel - 3M Dental Products- St Paul, MN 55144- USA) for 15 seconds, followed by rinsing for 30 seconds using air/water spray, dried with absorbing paper to remove excess water and keep the surface moist. Two layers of the adhesive system (Single Bond, 3M Dental ProductsSt Paul, MN 55144- USA) were applied and light cured for $20 \mathrm{sec}-$ onds. Afterwards, a hybrid composite resin (Filtek Z250, 3M Dental Products- St Paul, MN 55144- USA) was inserted in $1 \mathrm{~mm}$-thick increments. First, increments were placed obliquely against incisal and cervical walls, respectively, and the latest increment filled the cavity, each one being light cured for 40 seconds.

All specimens were stored in distilled water at $37{ }^{\circ} \mathrm{C} \pm 1{ }^{\circ} \mathrm{C}$ for 24 hours, and then, polished with wet flexible aluminum oxide disks (Sof-Lex Pop-on - 3M Dental Products- St Paul, MN 55144- USA).

Specimens were submitted to a thermocycling regimen of $500 \mathrm{cy}-$ cles between 5 and $55^{\circ} \mathrm{C}$ waterbaths. Dwell time was 1 minute, with a 3-second transfer time between baths. In preparation for dye penetration test, teeth were superficially dried, the apices of all teeth were sealed with epoxy resin and the entire tooth received two coats of nail varnish, except for a $2 \mathrm{~mm}$ window around restoration margins. As the nail varnish dried, teeth were immersed in distilled water for 2 hours, and then immersed in a 50\% silver nitrate aqueous solution for 8 hours, kept in a light-proof container.

Afterwards, the teeth were rinsed thoroughly in tap water and were embedded in chemically activated acrylic resin (JET, Classic, São Paulo - Brazil) and sectioned longitudinally in a mesiodistal direction with a water cooled diamond saw, in a sectioning machine (Minitom, Struers A/S, DK-2610, Copenhagen - Denmark), providing 3 sections of each restoration.

Next, the sections were exposed to the light of a photoflood lamp for 20 minutes to reveal the silver nitrate, which, exposed to light, acquires a dark color, allowing visualization of the dye-penetrated areas. Sections were initially thinned in a polishing machine (Politriz, Struers A/S, DK-2610, Copenhagen - Denmark), and then manually smoothed to obtain a flat surface and a final thickness of approximately $0.25 \mathrm{~mm}$.

The cuts were identified and carefully fixed on microscope slides, and the margins were analyzed separately; each margin was viewed under a $\times 5$ magnification optical microscope (Axiostar Plus, Carl Zeiss Vision GmbH, 85399 München-Hallbergmoos - Germany) connected with $\times 10$ magnification lens to a digital camera (Cyber-shot 3.3 MPEG Movie EX, model No. DSC-S75, Sony Corporation - Japan). The images obtained were transmitted to a personal computer and, after digitization, analyzed by the Axion Vision 3.1 software (Carl Zeiss Vision $\mathrm{GmbH}$, 85399 München-Hallbergmoos - Germany), which performs a standardized assessment of the tracer agent's extent along the margins and allows a quantitative measurement in millimeters. Depth of the cavity wall and dye penetration along occlusal and cervical margins toward axial wall were determined, and the percentage of dye penetration was calculated. Means of dye penetration for enamel and dentin interfaces were calculated for each group.

Data were assessed as to distribution and since it was not normal, a non-parametric analysis was chosen. Kruskal-Wallis test was used for comparisons among groups, and Wilcoxon test for margins.

\subsection{Shear bond strenght test}

The remaining 20 bovine incisors were sectioned on mesiodistal and occlusocervical directions, in such a way that 80 incisal surfaces (enamel) and 80 cervical surfaces (dentin) were obtained. The fragments were randomly divided into 4 groups, according to the lightcuring system, for tests on enamel and dentin $(n=20)$.

Sections were embedded in polyester resin using a $25 \mathrm{~mm}$ diameter $\times 1.0 \mathrm{~cm}$ high PVC ring, and submitted to mechanical polishing in water-cooled machine, either to flatten enamel (or remove it) or to expose superficial dentin. The flat, smooth dentin surfaces were polished with \#600-grit SiC paper for 30 seconds to produce a standardized smear layer.

Specimens were stored in distilled water at $4{ }^{\circ} \mathrm{C}$ during 24 hours for re-hydratation of dental tissues. To delimit the enamel and dentin-bonding sites, a small piece of insulating tape with a central orifice ( $2 \mathrm{~mm}$ diameter) was attached to specimen surface. The tape perforation was made by means of a modified rubber-dam punch to provide standardized orifices.

The delimited area was etched with a $35 \%$ phosphoric acid gel (Etching Gel - 3M Dental Products- St Paul, MN 55144-USA) during 15 seconds, followed by copiously rinsing with air/water spray during 30 seconds, and water excess removal by absorbing paper, leaving substrate slightly moist. Two layers of adhesive system (Single Bond - 3M Dental Products- St Paul, MN 55144- USA) were applied and light cured for 20 seconds with the tested light-curing units.

After bonding procedure, each specimen was fixed in a clamping metallic device (developed by Houston Biomaterial Research) in such way that the dentin site remained parallel to a flat surface. A split bisected Teflon ${ }^{\circledR}$ matrix ( $2 \mathrm{~mm}$ diameter) was positioned over the tooth/resin block resulting in a cylindrical cavity with the diameter coincident to the delimited bonding area. A hybrid lightcured composite resin (Filtek Z250 - 3M Dental Products- St Paul, MN 55144- USA) was inserted into the matrix in increments, being each increment polymerized for 40 seconds. As the matrix cavity was completely filled, the specimen was removed from the clamping device and the matrix was opened and separated, leaving a resin cylinder bonded to the delimited tooth surface. After a 24 hours 
storage period in distilled water at $37^{\circ} \mathrm{C}$, the specimens were tested for shear strength until failure in a universal testing machine (DL 2000, EMIC Equip. e sistemas de ensaios Ltda- São José dos Pinhais, CEP 83020-250 Brazil) at a crosshead speed of $0.5 \mathrm{~mm} / \mathrm{min}$ and a $50 \mathrm{kgf}$ load cell. Bond strength values were obtained in $\mathrm{kgf} . \mathrm{cm}^{-2}$ and after converted into MPa. Means and standard deviation were determined. As data distribution was normal, bond strength means were analyzed by two-way ANOVA. Multiple comparisons were done by Tukey's test at a 0.05 significance level. Fracture sites of specimens were observed with a $40 \mathrm{x}$ stereomicroscope to assess the failure modes, which were classified as adhesive, cohesive or mixed.

\section{Results}

\subsection{Microleakage test}

Means (\%) and standard deviations of marginal microleakage at incisal and cervical margins for the different groups are given on Table 2.

There was statistically significant difference $(\mathrm{p}<0.01)$ between the incisal and cervical margins. The cervical group presented the highest mean.

There were no significant differences among the light-curing units. When the incisal margins were assessed separately, no differences were found. However, when groups were assessed separately, only for cervical margins, a higher and statistically significant leakage $(p<0.05)$ was verified for group II, compared to groups III and IV, although being similar to group I.

\subsection{Shear bond strenght test}

Shear bond strength means and standard deviations are given on Table 3. It can be observed that there was no statistically significant difference $(p>0.05)$ between substrates and among groups, as also in their interaction.

The analysis of failure sites revealed that the adhesive-failure mode occurred predominantly for all tested devices.

Table 2. Means (\%) and standard deviations of dye penetration at occlusal and cervical margins.

\begin{tabular}{lcc}
\hline \multicolumn{1}{c}{ Groups } & Incisal margin & Cervical margin \\
\hline $\begin{array}{l}\text { Group I } \\
(\text { XL-3000) }\end{array}$ & $14.69( \pm 31.15)$ & $59.27( \pm 23.72)$ \\
$\begin{array}{l}\text { Group II } \\
(J e t L i t e ~ 4000)\end{array}$ & $22.30( \pm 30.32)$ & $76.95( \pm 19.43)$ \\
$\begin{array}{l}\text { Group III } \\
(\text { CL - K200) }\end{array}$ & $18.07( \pm 33.24)$ & $54.13( \pm 25.82)$ \\
$\begin{array}{l}\text { Group IV } \\
(\text { Ultraled })\end{array}$ & $23.48( \pm 31.36)$ & $55.96( \pm 20.38)$ \\
\hline
\end{tabular}

Table 3. Means (MPa) and standard deviations of bond strength at enamel and dentin for each group.

\begin{tabular}{lcc}
\hline \multicolumn{1}{c}{ Groups } & Enamel & Dentin \\
\hline $\begin{array}{l}\text { Group I } \\
(\text { XL-3000) }\end{array}$ & $21.51( \pm 4.72)$ & $21.46( \pm 6.76)$ \\
$\begin{array}{l}\text { Group II } \\
(\text { JetLite 4000) }\end{array}$ & $19.50( \pm 5.99)$ & $19.75( \pm 5.91)$ \\
$\begin{array}{l}\text { Group III } \\
(\text { CL }- \text { K200 })\end{array}$ & $19.91( \pm 5.02)$ & $21.57( \pm 7.10)$ \\
$\begin{array}{l}\text { Group IV } \\
(\text { Ultraled })\end{array}$ & $20.70( \pm 4.35)$ & $18.92( \pm 7.71)$ \\
\hline
\end{tabular}

\section{Discussion}

An important and crucial step to a successful restorative procedure is the polymerization of the adhesive system and composite resin, which is a paramount factor to attain accurate physical properties and good clinical performance of restorative materials ${ }^{18}$. When polymerization is not effective, some negative consequences may occur, such as postoperative sensitivity, decreased bond strength and increased marginal leakage, which is considered one of the main factors related to the longevity of restorations $\mathrm{s}^{13,19,20}$.

In the present study, a complete marginal sealing was not verified in the assessed experimental conditions, even using a cavity design with decreased dimensions and the incremental insertion technique.

However, incisal margins presented better marginal sealing than cervical margins. This finding can be clearly explained, as dentin still represents a major challenge to adhesion because it consists of a tubular tissue structure with fluids, which can restrict the impregnation of adhesive agents in the substrate ${ }^{21}$. Such results support literature findings ${ }^{22,23,24,25}$, which report a better behavior of enamel margins than cervical margins at dentin/cementum.

Among the tested-curing units, the marginal sealing observed with the LED lamp was similar to that found for conventional halogen light and Soft-Start technique, using moderate-end intensity. This result can be ascribed to the use of little increments during cavity filling, in addition to low intensity polymerization light, as a slow polymerization reaction of composite resin can cause less damage to the filling interface, by decreasing polymerization shrinkage stress ${ }^{14,26,27}$. Despite the low irradiance values demonstrated by LEDs on curing radiometers, LED units are more efficient in delivering usable light to photoactivate the camphoroquinone ${ }^{15}$.

Results found for the group using Soft-Start polymerization technique with moderate-end intensity are probably due the fact that this unit presents a low initial light intensity (around $50 \mathrm{~W} . \mathrm{cm}^{-2}$ ), which prolongs the period before reaching the gel point, increasing the flow capacity of the material, and a final intensity around $600 \mathrm{~mW} . \mathrm{cm}^{-2}$, which is necessary to achieve complete polymerization and optimal mechanical properties ${ }^{12,13,25,28,29}$. However, these properties were not extremely high, being similar to those observed with the same conventional halogen light system used in the present study. Similar results were found by Kubo et al..$^{30}$ in cervical cavities with a small C-factor. In the other hand, Santos et al. ${ }^{25}$ observed that the soft-start technique showed less microleakage for conventional curing mode. Ritter et al. ${ }^{31}$ and Attar et al. ${ }^{32}$ showed that there was no statistically significant difference in microleakage scores related to different light-curing units.

Nevertheless, when using Soft-Start curing technique with a high final intensity (Group II), a greater cervical leakage was observed because even with a progressive increase of its light intensity, the manufacturer states that this device works only at $25 \%$ of the programmed time on Soft-Start system, which is probably not enough to enable a slow polymerization reaction. In addition, it reaches extremely high values, which could lead to excessive polymerization shrinkage and marginal gaps, as the advantages of the initial slow polymerization (more elasticity and less material tension) obtained with the Soft-Start method can be lost due to a rise in total shrinkage when the final exposure is too high ${ }^{33}$.

These results are similar to those found by others authors ${ }^{34}$, who observed that the shrinkage rate for all light-curing techniques was greater during light polymerization reaction and continued so after removing the light source. This shrinkage may be attributed to a thermal contraction due to loss of radiant heat and the progressive cross-linking reaction in the resin phase of the materials, which occurred after light activation ${ }^{35}$. 
However, the use of different curing units with variable light intensities did not influence the shear strenght of the monocomponent adhesive system and the composite resin to bovine dentin. Similar results were found by Amaral et al. ${ }^{36}$, despite D'Alpino et al. ${ }^{37}$ observed that LED light provide significantly lower bond strength values then the conventional light curing, probably due to the narrow radiation spectrum emitted by the LED system ${ }^{37}$.

Such homogeneity on bond strength values is probably due to the fact that this test utilizes a configuration that minimizes shrinkage stress during sample preparation. Cavities, in contrast to flat surfaces, show a reduced free surface for shrinkage compensation by flow. Shrinkage stress is weak for configuration factors (C-Factors) lower than 1.0, and rises very quickly before leveling off at C-Factors over $3.0^{38}$.

Furthermore, during composite resin insertion, an incremental technique was used for all groups, with increments of $1 \mathrm{~mm}$ thick, minimizing dispersion caused by inorganic particles, which certainly decreases light intensity influence on complete polymerization in depth $^{18}$

This similarity of results can also be explained by the fact that light produced by LED is situated in a narrow band wavelength (450 a $490 \mathrm{~nm}$ ), which corresponds to canphoroquinone maximum absorption peak $(470 \mathrm{~nm})$, the main photoinitiator for polymerization of composite resins ${ }^{39}$. This light is formed by very close and highly energized colors, because the blue color has more energy than other wavelengths, producing greater polymerization efficiency even with lower power density.

Results obtained by Soft-Start technique can be explained by the fact that initial shrinkage is minimized by a gradual increase of light intensity at the first seconds of polymerization, because most of the polymerization shrinkage takes place at the first 20 seconds of curing $^{40}$. It is also during this period that most tension occurs within the bonding site. Therefore, it is important to use an exposure time that leads to least tension during this period, but still ensures the complete polymerization of the composite resin. One important way in which polymerization shrinkage can be controlled is by reducing polymerization speed. Feilzer et al. (1995) $)^{11}$ indicated that when polymerization of dental resins is accelerated, the molecular flow in the material is inhibited, thus causing inherent tension within the restoration, which may affect adhesion.

Thus, in the present study, only microleakage test, which involves a cavity with several walls to adhesion, was sensitive to the different polymerization techniques used. Further studies should be done, in such a way that the influence of the several cavity walls on adhesion integrity can be verified by using different photopolymerization sources.

\section{Conclusions}

Based on the methods used and results obtained in this study, it can be concluded that the use of the different light-curing systems did not affect the shear bond strength. Marginal leakage occurred in all specimens independently of the light-curing used, but cervical margin leakage was higher when the high-end light intensity softstart technique was used.

\section{Acknowledgments}

The authors would like to acknowledge CAPES and FAPESP for providing financial support and fellowship (n. 03/10960-0 and n.03/00498-7).

\section{References}

1. Blankenau RJ, Kelsey WP, Cavel WT, Blankenau P. Wavelength and intensity of seven systems for visible light-curing composite resins: a comparison study. Journal of the American Dental Association. 1983; 106(4): 471-474.

2. Nomoto R. Effect of light wavelength on polymerization of light-cured resins. Dental Materials Journal. 1997; 16(1): 60-73.

3. Fano L, Ma WY, Marcoli PA, Pizzi S, Fano V. Polymerization of dental composite resins using plasma light. Biomaterials. 2002; 23(4): 1011-1015.

4. Nomoto R., Uchida K, Hirasawa T. Effect of light intensity on polymerization of light-cured composite resins. Dental Materials Journal. 1994; 13(2):198-205.

5. Tate WH, Porter KH, Dosch RO. Successful photocuring: don't restore without it. Operative Dentistry. 1999; 24(2): 109-114.

6. Lee SY, Greener EH. Effect of excitation energy on dentine bond strength and composite properties. Journal of Dentistry. 1994; 22(3): 175-181.

7. Tarle Z, Meniga A, Knezevic A, Sutalo J, Ristic M, Pichler G. Composite conversion and temperature rise using a conventional, plasma arc, and an experimental blue LED curing unit. Journal of Oral Rehabilitation. 2002; 29(7): 662-667.

8. Kleverlaan CJ, de Gee AJ. Curing efficiency and heat generation of various resin composites cured with high-intensity halogen lights. European Journal of Oral Sciences. 2004; 112(1): 84-88.

9. Mandras RS, Retief DH, Russell CM. The effects of thermal and occlusal stresses on the microleakage of the Scotchbond 2 dentinal bonding system. Dental Materials. 1991; 7(1): 63-67.

10. Davidson CL, Feilzer AJ. Polymerization shrinkage and polymerization shrinkage stress in polymer-based restoratives. Journal of Dentistry. 1997; 25(6): 435-440.

11. Feilzer AJ, Dooren LH, de Gee AJ, Davidson CL. Influence of light intensity on polymerization shrinkage and integrity of restoration-cavity interface. European Journal of Oral Sciences. 1995; 103(5): 322-326.

12. Friedl KH, Schmalz G, Hiller KA, Markl A. Marginal adaption of Class $\mathrm{V}$ restorations with and without "softstart-polymerization". Operative Dentistry. 2000; 25(1): 26-32.

13. Mehl A, Hickel R, Kunzelmann KH. Physical properties and gap formation of light-cured composites with and without soft-start polymerization. Journal of Dentistry. 1997; 25(3-4): 321-330.

14. Jandt KD, Mills RW, Blackwell GB, Ashworth SH. Depth of cure and compressive strength of dental composites cured with blue light emitting diodes. Dental Materials. 2000; 16(1): 41-47.

15. Althoff $\mathrm{O}$, Hartung M. Advances in light curing. American Journal of Dentistry. 2000; 13(Special Issue): 77d-81d.

16. Knezevic A, Tarle Z, Meniga A, Sutalo J, Pichler G, Ristic M. Degree of conversion and temperature rise during polymerization of composite resin samples with blue diodes. Journal of Oral Rehabilitation. 2001; 28(6): 586-591.

17. Christensen RP, Palmer T, Ploeger B, Yost M. Resin polymerization problems - are they caused by resin curing lights, resin formulations, or both?. Compendium of Continuing Education in Dentistry. 1999; 20(sup 25): S42-54.

18. Bayne SC, Heymann HO, Swift Jr EJ. Update on dental composite restorations. Journal of the American Dental Association. 1994; 125(6): 687-701.

19. Going RE. Microleakage around dental restorations: a summarizing review. Journal of the American Dental Association.1972; 84(6): 1349-1357.

20. Opdam NJ, Roeters FJ, Feilzer AJ, Verdonschot EH. Marginal integrity and postoperative sensitivity in Class 2 resin composite restorations in vivo. Journal of Dentistry. 1998; 26(7): 555-562.

21. Pashley DH, Carvalho RM. Dentine permeability and dentine adhesion. Journal of Dentistry. 1997; 25(5): 355-372

22. Corona SAM, Borsatto MC, Palma-Dibb RG, Ramos RP, Brugnera A, Pécora JD. Microleakage of class V composite restorations after bur, airabrasion or Er:YAG laser preparation. Operative Dentistry. 2001; 26(5): 491-497. 
23. Palma-Dibb RG, Corona SAM, Borsatto MC, Ramos RP, Pécora JD. Assessing microleakage on class V composite resin restorations after Er:YAG laser preparation varying the adhesive systems. Journal of Clinical Laser Medicine and Surgery. 2002; 20(3): 129-133.

24. Yazici AR, Özgünaltay G, Dayangaç BA. Scanning electron microscopic study of different caries removal techniques of human dentin. Operative Dentistry. 2002; 27(4): 360-366.

25. Santos AJ, Lisso MT, Aguiar FH, França FM, Lovadino JR. Effect of stepped exposure on quantitative in vitro marginal microleakage. Journal Esthetic Restorative Dentistry. 2005; 17(4): 236-242.

26. Oberholzer TG, Schunemann M, Kidd M. Effect of LED curing on microleakage and microhardness of Class $\mathrm{V}$ resin-based composite restorations. International Dental Journal. 2004; 54(1): 15-20.

27. Stahl F, Ashworth SH, Jandt KD, Mills RW. Light-emitting diode (LED) polymerisation of dental composites: flexural properties and polymerisation potential. Biomaterials. 2000; 21(13): 1379-1385.

28. Amaral CM, de Castro AK, Pimenta LA, Ambrosano GM. Influence of resin composite polymerization techniques on microleakage and microhardness. Quintessence International. 2002; 33(9): 685-689.

29. Yoshikawa T, Burrow MF, Tagami J. A light curing method for improving marginal sealing and cavity wall adaptation of resin composite restorations. Dental Materials. 2001; 17(4): 359-366.

30. Kubo S, Yokota H, Yokota H, Hayashi Y. The effect of light-curing modes on the microleakage of cervical resin composite restorations. Journal of Dentistry. 2004; 32(3): 247-254.

31. Ritter AV, Cavalcante LM, Swift EJ Jr, Thompson JY, Pimenta LA. Effect of light-curing method on marginal adaptation, microleakage, and microhardness of composite restorations. Biomaterials. 2006; 78(2): 302-311.

32. Attar N, Korkmaz Y. Effect of two light-emitting diode (LED) and one halogen curing light on the microleakage of Class V flowable composite restorations. Journal Contemporaine Dental Pratic. 2007; 8(2): 80-88.

33. Oberholzer TG, Preez ICD, Kidd M. Effect of LED curing on the microleakege, shear bond strength and surface hardness of a resin-based composite restoration. Biomaterials. 2005; 26(18): 3981-3986.

34. Soh MS, Yap AU, Siow KS. Post-gel shrinkage with different modes of LED and halogen light curing units. Operative Dentistry. 2004; 29(3): 317-324.

35. Yap AU, Wang HB, Siow KS, Gan LM. Polymerization shrinkage of visible light-cured composites. Operative Dentistry. 2000; 25(2): 98-103.

36. Amaral CM, Peris AR, Ambrosano GMB, Swift Jr EJ, Pimenta LA. The effest of light-curins source and mode on microtensile Bond strength to bovine dentin. Journal Adhesive of Dentistry. 2006; 8(1): 41-45.

37. D'Alpino PH, Wang L, Rueggeberg FA, Svizero NR, Pereira JC, Pashley $\mathrm{DH}$, Carvalho RM. Bond strength of resin-based restorations polymerized with different light-curing sources. Journal Adhesive of dentistry. 2006; 8(5): 293-298.

38. Feilzer AJ, de Gee AJ, Davidison CL. Quantitative determination of stress reduction by flow in composite restorations. Dental Materials. 1990; 6(3): 167-171.

39. Mills RW, Jandt KD, Ashworth SH. Dental composite depth of cure with halogen and blue light emitting diode technology. Brazilian of Dental Journal. 1999; 186(8): 338-391.

40. Dennison JB, Yaman P, Seir R, Hamilton J. Effect of variable light intensity on composite shrinkage. Journal of Prosthetic Dentistry. 2000; 84(5): 499-505 
